\title{
PRODUÇÃO E CARACTERIZAÇÃO DE PROLIPOSSOMAS POR RECOBRIMENTO DE SACAROSE MICRONIZADA
}

\author{
G.S. Silva, C.G. Jange, S.C. Pinho* \\ Universidade de São Paulo (USP), Faculdade de Zootecnia e Engenharia de \\ Alimentos (FZEA), Departamento de Engenharia de Alimentos \\ *e-mail: samantha@usp.br
}

\begin{abstract}
RESUMO
A maioria das técnicas de produção de lipossomas apresenta desvantagens em termos de capacidade de escalonamento, provavelmente devido à complexidade deste processo e a típica baixa reprodutibilidade. A técnica proposta neste trabalho pretende ser uma alternativa para o escalonamento da produção de para o uso na indústria de alimentos, principalmente devido à sua simplicidade e ausência de solventes orgânicos. $\mathrm{O}$ método consiste no recobrimento de sacarose micronizada por fosfolipídio previamente solubilizado em etanol, usando-se evaporação do solvente sob vácuo (em rotaevaporador). Utilizando-se a concentração de 3,2\% de fosfolipídio em solução de etanol gotejada em sacarose micronizada com tamanho inferior a $100 \mu \mathrm{M}$, foi possível observar constatar que o açúcar foi completamente recoberto pelo fosfolipídio, através de microscopia eletrônica de varredura. Além disso, o pó obtido se mostrou amorfo e solubilidade de $98 \%$ em água, fatores extremamente importantes para a etapa de hidratação dos prolipossomas. Os prolipossomas também se mostraram com baixíssima capacidade de retenção de umidade, característica importante para determinar sua vida de prateleira durante o armazenamento.
\end{abstract}

\section{INTRODUÇÃO}

O maior interesse do consumidor por alimentos mais saudáveis e que tragam beneficio a saúde abre espaço para o desenvolvimento de novos métodos de processamento e tecnologias que tornem possível a sua produção em grande escala. Alimentos que têm em sua formulação substâncias que façam bem a saúde - os alimentos ditos funcionais - se torna bastante atrativo nos dias atuais para os consumidores

Entretanto, diversos bioativos são de difícil incorporação em alimentos devido à sua hidrofobicidade (p.ex., carotenoides, curcuminoides, flavonoides). Dentre os bioaativos hidrofóbicos mais estudados atualmente, está a curcumina, que é também uma alternativa para substituições de corantes amarelo, potencialmente alergênicos (Moutinho et al., 2007). Este curcuminoide possui alto poder antioxidante a curcumina é um composto fenólico e trata-se de um pigmento amarelo hidrofóbico extraído dos rizomas da planta Curcuma longa L., que no Brasil é conhecida como curcuma, batatinhaamarela, grengibre dourado, mangarataia, açafrão da índia ou açafrão da terra (Rosa, 2009; Srivastava et al. 2011).

Além disso, a hidrofobicidade de uma substância, de modo geral, diminui sua biodisponibilidade. Desta forma, para que sejam incorporados adequadamente em diversas formulações alimentícias, torna-se 
necessária a sua encapsulação em matrizes lipídicas capazes de serem dispersas em meios aquosos, como emulsões, nanoemulsões, partículas lipídicas sólidas e lipossomas.

Lipossomas são definidos como estruturas esféricas em que a fase aquosa é encapsulada por uma ou mais bicamadas de fosfolipídios, na forma de vesículas fosfolipídicas. Seu diâmetro pode variar de 20 nanômetros a poucos micrômetros, enquanto a espessura de cada bicamada é, tipicamente, da ordem de 4 nanômetros (LASIC,1993). São amplamente utilizados para encapsular vários compostos, devido à sua versatilidade estrutural em termos do tamanho, composição e facilidade de incorporar substâncias hidrofílicas e hidrofóbicas (Mozafari et al., 2008). Existem diversas técnicas de produção que podem ser utilizadas para obtenção dos lipossomas. A escolha do método depende principalmente do tipo e do tamanho do lipossoma que se pretende produzir e o objetivo final da aplicação das vesículas (MALMSTEN, 2002).

Dentre as vantagens para sua aplicação em alimentos estão, além desta versatilidade, sua total biodegradabilidade e baixíssima toxicidade (Taylor et al., 2005). Dentre os grandes desafios a serem superados para que o emprego de lipossomas na indústria alimentícia seja vislumbrado como realmente viável está a dificuldade de produção em grande escala e a impossibilidade do uso de solventes orgânicos utilizados na indústria farmacêutica (Toniazzo et al., 2014). O uso de prolipossomas surge como uma alternativa para superar ambos os problemas citados. $\mathrm{O}$ método dos prolipossomas baseia-se inicialmente na preparação de uma mistura seca de lipídios, com posterior formação dos lipossomas do tipo multilamelares por hidratação destas misturas secas de fosfolipídios. Tais partículas secas podem, por exemplo, produzidas por spray-drying. Neste caso, a maior vantagem é que são formadas estruturas amorfas, muito mais fáceis de hidratar quando comparado com outros métodos convencionais de formação de lipossomas.

Entretanto, a utilização do método de spray drying para a obtenção dos prolipossomas (partículas secas de fosfolipídios) é seu baixo rendimento, especialmente em escala laboratorial (Toniazzo, 2013). Um método alternativo para a produção dos prolipossomas foi proposto por Elhissi et al. (2006), que consiste em recobrir um carreador (sacarose, por exemplo) micronizado com fosfolipídios, através da injeção de uma solução etanólica em ambiente despressurizado (sob evaporação rotativa a vácuo, por exemplo). Desta forma, pode-se obter um pó micronizado recoberto pelos fosfolipídios (bem como pelo bioativo a ser encapsulado) que pode ser posteriormente hidratado, e as dispersões aquosas de lipossomas, obtidas.

Neste estudo, foram determinadas condições operacionais para obtenção de prolipossomas através do método descrito inicialmente por Elhissi et al. (2006) e Elhissi et al. (2012), ou seja, pelo recobrimento de sacarose micronizada por fosfolipídios, em evaporador rotativo à vácuo, em escala de laboratório. $\mathrm{O}$ bioativo incorporado na formulação foi a curcumina. Os prolipossomas foram caracterizados em termos de morfologia (por microscopia eletrônica de varredura), cristalinidade (por difratometria de raios-X) e capacidade de absorção de umidade.

\section{MÉTODOS}

2.1. Produção dos prolipossomas por recobrimento de sacarose micronizada

Primeiramente, a sacarose (Synth, Diadema, SP, Brasil) foi micronizada em moinho de bolas de zircônio. Cem mililitros de solução etanólica (etanol anidro, Dinâmica) contendo $3,2 \mathrm{~g}$ de fosfolipídio 
(fosfatidilcolina de soja hidrogenada e purificada, Phospholipon 90H, Lipoid, Ludwigshafen, Alemanha) e $60 \mathrm{mg}$ de curcumina (Sigma, St. Louis, MO, EUA) foi injetada em sobre a sacarose previamente micronizada. $\mathrm{O}$ processo de injeção da solução etanólica foi feito em um rotaevaporador de forma contínua com $\mathrm{o}$ auxilio de bomba peristáltica (modelo Masterflex 7528-30, Cole-Parmer, Vernon Hills, IL, EUA) em uma vazão de 4,06 $\mathrm{mL} /$ minuto. $\mathrm{O}$ balão rotativo foi mantido a 45 $\pm 2{ }^{\circ} \mathrm{C}$ para evaporação do etanol. A Figura 1 mostra a montagem utilizada para produção dos prolipossomas por recobrimento da sacarose micronizada:

Figura 1 - Sistema de produção de prolipossomas por recobrimento de sacarose micronizada: (A) balão rotativo contendo sacarose micronizada; (B) entrada de solução etanólica contendo 3,2\% de fosfolipídio; (C) balão de recepção de etanol condensado; (D) bomba à vácuo.; (E) bomba peristáltica.

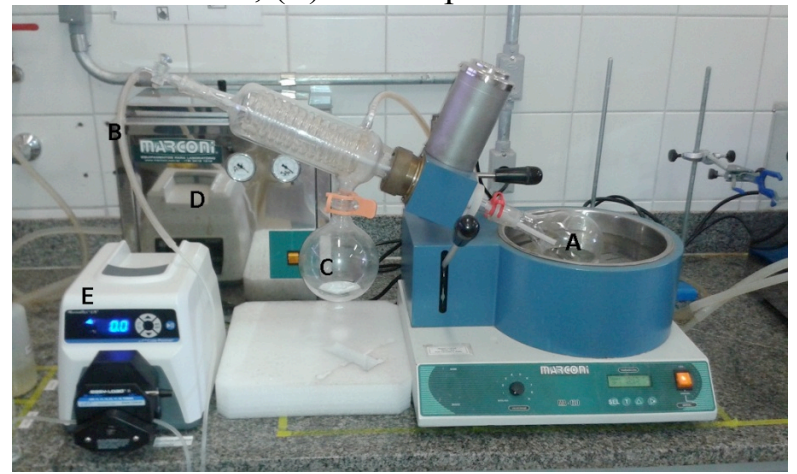

\subsection{Microscopia eletrônica de varredura (MEV)}

A morfologia das partículas dos prolipossomas foi visualizada por meio de um microscópio eletrônico de varredura (modelo TM 3000, Tabletop Microscope Hitachi, Tóquio, Japão), utilizando-se o software TM3000 (acoplado ao equipamento). Para a microscopias as amostras foram acondicionadas em fita de carbono dupla face e estas foram fixadas em stubs de aluminio. As imagens foram capturadas com aceleração da voltagem de $5 \mathrm{KV}$ com corrente de 1750 $\mathrm{mA}$.

\subsection{Difratometria de raios-X (DRX)}

As análises de difratometria de raios- $X$ foram realizadas em equipamento de difração de raio X modelo MiniFlex600 com tubo de ânodo de cobre com $\lambda=1,5418$ ângstrons e monocromador de grafite para feixe difratado. A varredura foi feita no intervalo de $2 \mathrm{q}$ de 5 a $40^{\circ}$, em passos de $0,02^{\circ}$, à velocidade de $2 \%$ min.

\subsection{Espectroscopia de infravermelho com transformada de Fourier (FTIR)}

Os espectros na região do infravermelho para prolipossomas foram obtidos na região de comprimentos de onda de 4000 a $4000 \mathrm{~cm}^{-1}$ utilizando-se um equipamento Perkin Elmer FT-IR Spectrometer (Waltham, MA, EUA) com o auxílio do software Spectrum One versão 5.3.1.

\subsection{Obtenção das isotermas de sorção de umidade}

As umidades de equilíbrio das amostras em pó foram determinadas pelo método gravimétrico estático (LABUZA, 1984), utilizando-se soluções salinas saturadas em água destilada, para uma determinada faixa de umidade relativa. As soluções salinas utilizadas bem como as atividades de água correspondentes, que forma determinadas experimentalmente do AQUALAB (modelo Series 3 TE, Decagon Devices, Pullman, WA, EUA).

\subsection{Teor de umidade}

O teor de umidade foi medido em um analisador de umidade (modelo MB35, Hohaus, Nova Jersey, EUA) utilizando radiação infravermelho de uma fonte de 


\section{ENEMP \\ CONGRESSO BRASILEIRO \\ São Carlos - SP}

halogênio, tendo sido o resultado foi expresso em base seca.

\subsection{Solubilidade}

A solubilidade foi determinada de acordo com o método de Eastman e Moore (1984). O método consistiu na adição de $0,5 \mathrm{~g}$ de amostra de pó em um recipiente contendo 50 $\mathrm{mL}$ de água destilada, sob agitação $100 \mathrm{rpm}$ em uma mesa orbital (TECNAL) por 30 minutos, seguida por centrifugação a 3000 RPM por 5 minutos. Posteriormente, uma alíquota de $25 \mathrm{ml}$ do sobrenadante foi retirada e levada para estufa a $105{ }^{\circ} \mathrm{C}$ até o peso constante. A solubilidade foi calculada com base no peso inicial de amostra que foi solubilizada nessa alíquota do sobrenadante. $\mathrm{O}$ resultado foi expresso em porcentagem.

\subsection{Higroscopicidade}

Pró-liposomas foram caracterizados em termos de higroscopicidade de acordo com o procedimento descrito por Cai \&Corke (2000). Triplicatas de amostras contendo $0,2 \mathrm{~g}$ foram dispostas em pesa-filtros e posteriormente acondicionadas por sete dias em dessecador contendo solução saturada de cloreto de sódio (umidade relativa 75,3\%). A higroscopicidade foi medida através da massa de água absorvida pela amostra, e expressa em g de água adsorvida/100 mg de matéria seca.

\section{RESULTADOS}

3.1. Morfologia das partículas de prolipossomas por microscopia eletrônica de varredura (MEV)

As micrografias obtidas por MEV dos prolipossomas estão mostradas na Figura 2. Observa-se claramente que o aspecto visual dos prolipossomas é bem diferente dos componentes puros (fosfolipídio e sacarose micronizada). A sacarose micronizada tem um aspecto cristalino, ao passo que o fosfolipídio puro tem um aspecto amorfo, e o prolipossoma se assemelha a uma estrutura recoberta (é possível perceber alteração na superfície do material comparando-se as micrografias 2(A) e 2(B)). Este tipo de morfologia foi observada em todos os campos analisados, o que leva a crer que a quantidade de material fosfolipídico e de sacarose foram adequados, levando a um recobrimento bem sucedido.

Figura 2. Micrografias obtidas por microscopia eletrônica de varredura das amostras:(A) fosfolipídio Phospholipon 90H, (B) sacarose micronizada; (C) prolipossomas.
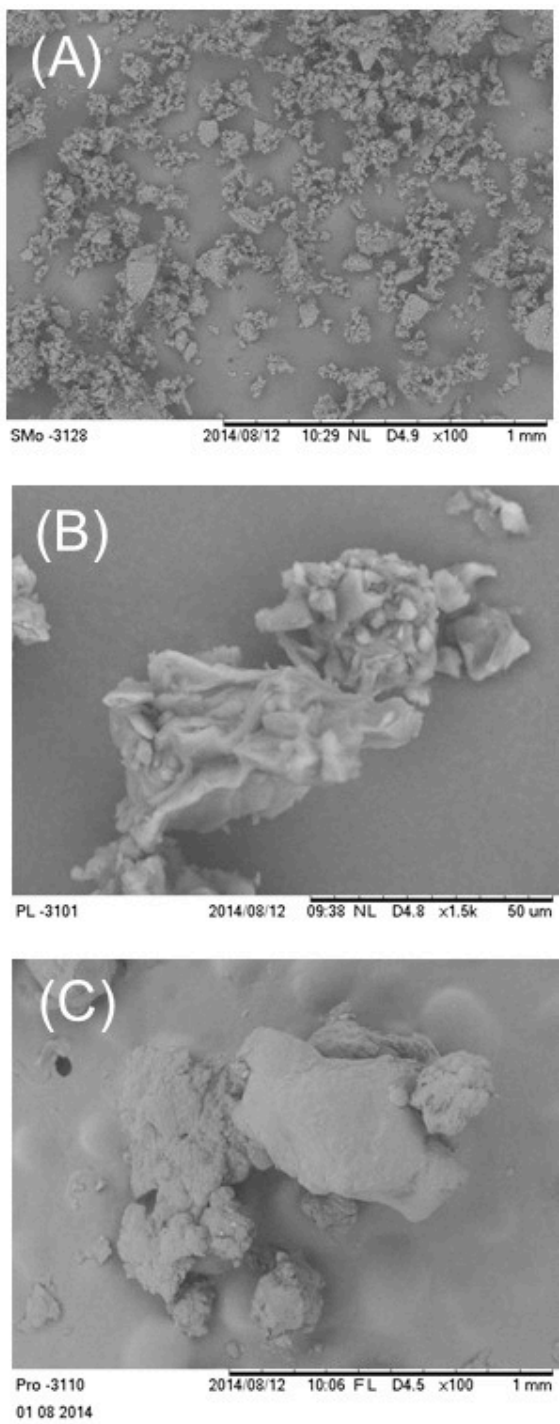

3.2. Espectroscopia de infravermelho 
Os resultados obtidos pelas análises de espectroscopia na região do infravermelho são mostradas na Figura 3. Os espectros de absorbância são idênticos, mostrando que a presença da curcumina não modificou quimicamente a estrutura dos prolipossomas obtidos. Além disso, os espectros mostram que houve um recobrimento da sacarose pelos fosfolipídios, e não interação química entre estes dois componentes da formulação. $\mathrm{O}$ fenômeno que tipicamente evidenciaria uma formação de uma interação forte entre os fosfolipídios e a sacarose seria a diminuição ou eventual eliminação dos picos a 1235 e $1735 \mathrm{~cm}^{-1}$, o que não ocorreu (Yoshida et al., 2010). Estes picos estão relacionados com o estiramento do grupo $\mathrm{P}=\mathrm{O}$ e $\mathrm{C}=\mathrm{O}$, respectivamente, dos grupos ésteres, presentes nas cabeças polares dos fosfolipídios.

Figura 3. Espectros de infravermelho obtidos para as amostras de prolipossomas produzidas.

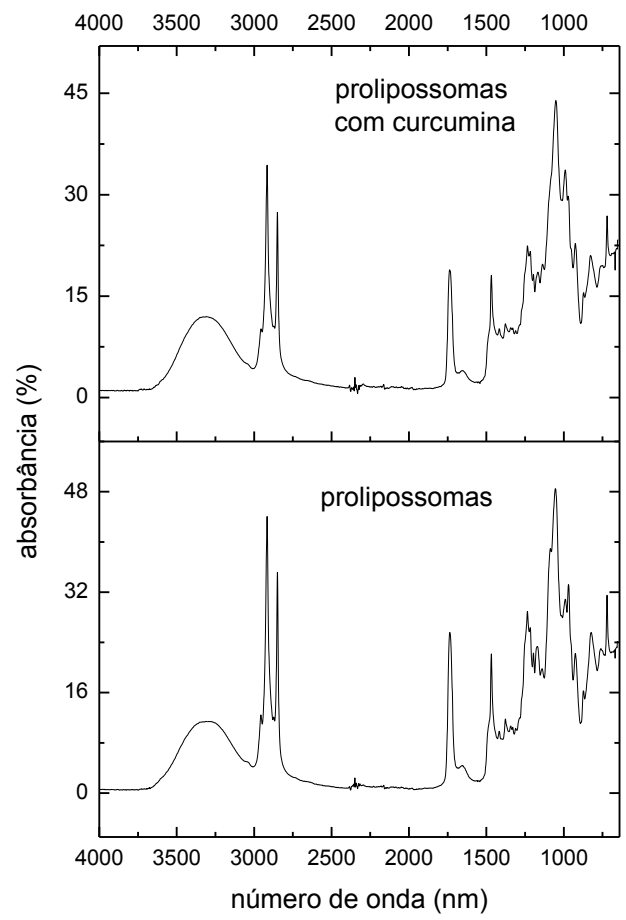

3.3. Difratometria de raios- $X$
Os resultados das análises de difratometria de raios-X estão mostrados na Figura 3. Os difratogramas de raios-X mostram que os prolipossomas são uma mistura física dos seus componentes, pois são encontrados picos (Figura 4) típicos de fosfolipídios (a 21.4॰, o único no difratograma do fosfolipídio puro), bem como da sacarose e da curcumina. Os valores de intensidade de difração indicam que os prolipossomas são estruturas mais amorfas que a sacarose e a curcumina puras, o que é de importância fundamental para a sua posterior hidratação e formação das dispersões aquosas de vesículas lipossomais (Moraes et al., 2013; Alves e Santana, 2004).

Figura 3. Difratogramas de raios- $X$ das amostras de matérias-primas e prolipossomas.

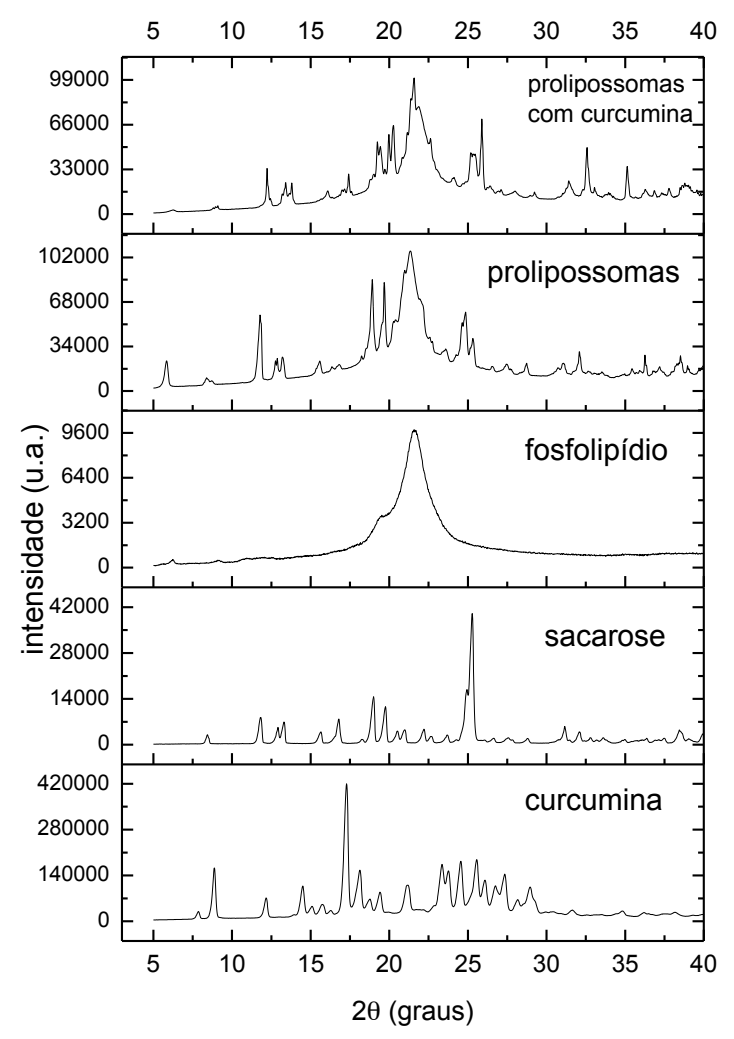

3.4. Solubilidade e absorção de água 
É de fundamental importância que os prolipossomas tenham um alto valor de solubilidade, uma vez que serão posteriormente hidratados para obtenção dos lipossomas em dispersão aquosa. A Tabela 1 mostra os dados obtidos em relação à solubilidade e capacidade de absorção de água pelos prolipossomas produzidos. $\mathrm{O}$ valor de solubilidade, pela metodologia testada, foi de praticamente $100 \%$ do pó utilizado.

Tabela 1: Solubilidade, higroscopicidade e teor de umidade dos prolipossomas.

\begin{tabular}{cc}
\hline Parâmetro & Valor \\
\hline Solubilidade & $98,6 \%$ \\
Higroscopicidade & $5,68 \%$ \\
Umidade (dia 0) & $2,1 \%$ \\
\hline
\end{tabular}

Os valores de higroscopicidade mostram que os pós de prolipossomas absorvem muito pouca água, mesmo quando em condição de alta umidade, fato confirmado pelas isotermas de sorção obtidas e mostradas na Figura 4:

Figura 4. Isotermas de sorção de umidade obtidas para os prolipossomas.

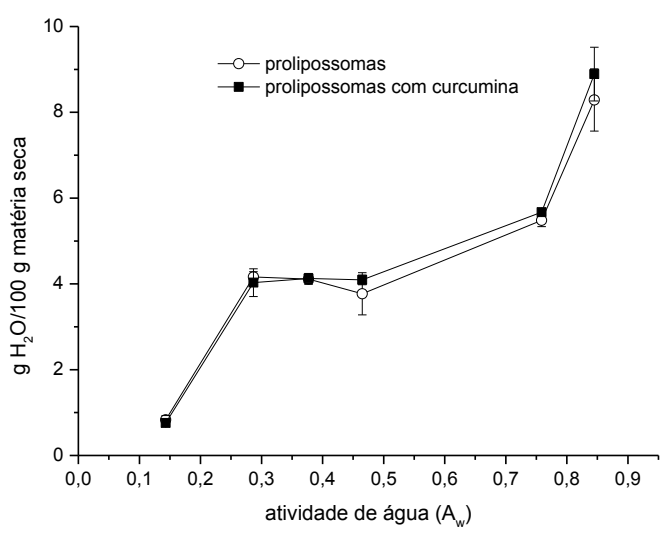

Tanto nos prolipossomas sem curcumina quanto nos prolipossomas contendo curcumina, a sorção de umidade pelos pós foi baixíssima, e praticamente idêntica nos dois casos. Tais resultados são muito interessantes, pois mostram que os prolipossomas poderão ser armazenados em diferentes condições de umidade, sem grandes prejuízos à sua integridade.

\section{CONCLUSÕES}

A produção de prolipossomas foi eita por recobrimento com sacarose utilizando-se a concentração de 3,2\% de fosfolipídio em solução de etanol gotejada em sacarose micronizada, foi possível constatar que o açúcar foi completamente recoberto pelo fosfolipídio, através de microscopia eletrônica de varredura. Além disso, o pó obtido se mostrou amorfo e com solubilidade de $98 \%$ em água, fatores extremamente importantes para a etapa posterior de hidratação dos prolipossomas para formação das vesículas em dispersão. Os prolipossomas também se mostraram com baixíssima capacidade de retenção de umidade, característica importante para aumentar sua vida de prateleira durante o armazenamento.

\section{REFERÊNCIAS}

ELHISSI, A. M. A. et al. A calorimetric study of dimyristoylphosphatidylcholine phase transitions and steroid-liposome interactions for liposomes prepared by thin film and proliposome methods. International journal of pharmaceutics, v. 320, n. 1, p. 124-130, 2006.

ELHISSI, Abdelbary MA et al. A study of size, microscopic morphology, and dispersion mechanism of structures generated on hydration of proliposomes. Journal of Dispersion Science and Technology, v. 33, n. 8, p. 1121-1126, 2012.

LASIC, D.D. Liposomes: from fhysics to applications. $1^{\text {a }}$ ed. Amsterdam: Elsevier, 1993.

MALMSTEN, M. Surfactants and Polymers in Drug Delivery. New York: Marcel Dekker, 2002.

MOZAFARI, M. R.; JOHNSON, C.; HATZIANTONIOU, s.; DEMETZOS, c. Nanoliposomes and Their Applications in Food Nanotechnology, Journal of Liposome Research, v. 18, 309-327, 2008.

ROSA, CARLA DE OLIVEIRA BARBOSA. AVALIAÇÃO DO EFEITO DE COMPOSTOS 
NATURAIS-CURCUMINA E HESPERIDINA-NA HIPERLIPIDEMIA INDUZIDA EM COELHOS. 2009. Tese de Doutorado. Universidade Federal de Viçosa.

SRIVASTAVA, Sharad; MEHROTRA, Shanta; RAWAT, A. K. S. Pharmacognostic evaluation of the rhizomes of Curcuma zedoaria Rosc. Pharmacognosy Journal, v. 3, n. 20, p. 20-26, 2011.

TAYLOR, T. M.; WEISS, J.; DAVIDSON, P. M.; BRUCE, B. D. Liposomal Nanocapsules in Food Science and Agriculture. Food Science and Nutrition, v. 45, 587-605, 2005.

TONIAZZO, Taíse et al. $\beta$-carotene-loaded liposome dispersions stabilized with xanthan and guar gums: Physico-chemical stability and feasibility of application in yogurt. LWT-Food Science and Technology, v. 59, n. 2, p. 1265-1273, 2014.

TONIAZZO, Taíse. Dispersões de lipossomas encapsulando $\beta$-caroteno: caracterização, estabilidade físico-química e incorporação em iogurte. dissertação de mestrado. Universidade de São Paulo.

\section{AGRADECIMENTOS}

Os autores agradecem à FAPESP pela bolsa de Iniciação Científica concedida (processo 2014/23376-9). 